\title{
ZAGADNIENIE ACZASOWEGO CHARAKTERU WSZECHŚWIATA W UJĘCIU TEORII KOSMOLOGICZNYCH
}

Nowe odkrycia dokonane na poziomie kosmologicznym i mikrokosmicznym oraz nowe rozwiązania teoretyczne, których nie można pogodzić z tradycyjnymi intuicyjno-zdroworozsądkowymi ujęciami, pozwalają lepiej zrozumieć zróżnicowanie struktur istniejącej obiektywnie rzeczywistości oraz głębiej uświadomić ograniczoność i aproksymatywność ludzkiego poznania. Konsekwencją nowych ujęć jest $m$. in. wniosek, iż ekstrapolowanie na cały wszechświat pewnych właściwości materii badanych w układach dostępnych obecnie do obserwacji jest pod względem metodologicznym podobnie nieuprawnione, jak nieuprawniony byłby wniosek Marsjan, którzy po wylądowaniu w środku jeziora Erie twierdziliby, że kulista Ziemia jest jednostajnie pokryta słodką wodą ${ }^{1}$.

Ekstrapolacyjna ostrożność skłania kosmologów do uwzględnienia możliwości, iż w krańcowych rejonach fizykalnych badań mogą nie obowiązywać uznawane za podstawowe prawa ziemskiej fizyki, zaś terminy takie, jak czas, przestrzeń, determinizm mogą się okazać terminami pustymi ${ }^{2}$. Konsekwencje takiego stanu mogą okazać się doniosłymi dla filozofii przyrody, ponieważ upoważniają one do pytania, czy w dotychczasowym studium filozoficznym nie popełniono błędu bezzasadnej ekstrapolacji na ws zystkie obiekty materialne pewnych cech i prawidłowości posiadających jedynie $1 \mathrm{ok}$ alny charakter. Stąd też mając na uwadze doniosłą rolę, jaką w analizach filozoficznych pełni pojęcie czasu, celowym będzie zbadanie w niniejszym artykule teorii kosmologicznych, w których dopuszcza się możliwość istnienia wszechświata

Zob. C. G. Callan, R. H. Dicke, P. J. E. Peebles, ,.Amer. J. Phys.", 33 (1965) 105.

2 Por.G. I. Naan, Riewolucija w astronomii, w: Zwiezdy i wsielennaja, Moskwa 1966,21 . 
aczasowego, w jakim nie można określić kierunku upływu czasu czy przeprowadzić pomiarów czasu.

1. Z Newtonowską koncepcją czasu absolutnego nie można pogodzić występowania zdarzeń aczasoprzestrzennych, lecz każdemu zdarzeniu przypisać trzeba określony moment i punkt przestrzeni. Aczasowość mogłaby w tej koncepcji mieć jedynie charakter subiektywny i byłaby rezultatem niemożności pomiaru istniejącego obiektywnie czasu przez danego obserwatora. Współczesna fizyka odeszła jednak od Newtonowskiego ujęcia czasu obdarzonego istnieniem niezależnym od istnienia materii, zaś jej empiriometryczne ujęcie czasu harmonizuje z relacyjną koncepcją Leibniza czy ze scholastycznym pojmowaniem czasu jako ens rationis cum fundamento in re. Sporadycznie można wprawdzie spotykać u fizyków utrzymane w Newtonowskim duchu określenia czasu jako „,tego co się dzieje, kiedy nic się nie dzieje" 3, z kontekstu podobnych wypowiedzi wynika jednak, że sami autorzy nie przywiązują do nich większej wagi, zaznaczając, że interesuje ich nie tyle natura czasu, co możliwości p o m i a r u czasu. Aby możliwy był natomiast pomiar czasu, konieczne jest eksperymentalne porównanie interwału, jaki upłynął między dwoma różniącymi się wzajemnie stanami układu i jednostkowym interwałem czasu. W tym celu do sensownego semantycznie odrtoszenia pojęć czasowych na określone stany materii konieczne jest:

I. Przyjęcie jednostki pomiaru czasu.

II. Istnienie procesów chronometrykalnych; znaczy to, iż w procesie rozwoju układu występują różniące się od siebie stany $C_{1}, C_{2} \ldots C_{n}$ określone odpowiednimi parametrami $\left(\mathrm{p}_{1} \cdot \mathrm{q}_{1} \cdot \mathrm{r}_{1} \ldots\right),\left(\mathrm{p}_{2} \cdot \mathrm{q}_{2} \cdot \mathrm{r}_{2} \ldots\right) \ldots\left(\mathrm{p}_{\mathrm{n}} \cdot \mathrm{q}_{\mathrm{n}}\right.$. $\left.\cdot r_{\mathrm{n}} \ldots\right)$.

III. Możliwość przeprowadzenia odpowiednich obserwacji, pomiarów i porównań ${ }^{4}$.

2. Gdyby któryś z wymienionych warunków nie mógł być spełniony, niemożliwa byłaby charakterystyka temporalna danego obiektu i skutkiem tego nie można by w sposób semantycznie sensowny orzekać o jego wcześniejszych stanach czy odwiecznym istnieniu. W różnych teoriach kosmologicznych traktuje się, w sposób mniej czy bardziej wyraźny, możliwość niespełnienia któregoś z tych warunków jako ewentualność, której nie sposób wykluczyć. I nie są to nawet rozwiązania najnowsze. Już w klasycznej koncepcji Lemaître’a wątpliwe było odnoszenie pojęć

3 R. P. Feynman, R. B. Leighton, M. Sands, Feynmana wykłady z fizyki, t. 1, cz. 1, Warszawa $1974^{3}, 76$.

${ }_{4}$ Por. W. A. Szpolanskij, Chronomietrija, Moskwa 1974, 51-54. 
czasowych do wyjściowego stanu rozwoju pierwotnego atomu. Trudności, jakie wyłaniały się przy tym zadaniu, wynikały zarówno z niemożności rozróżnienia między dwoma stanami w układzie, który jest maksymalnie nieskomplikowany, jak i z niemożności wybrania jednostki czasu dla stanu najwyższej prostoty. Sam twórca modelu stwierdzał w tym przedmiocie: „Ściśle mówiąc, jeśliby materia istniała jako pojedyncze jądro atomowe, nie byłoby sensownym orzekanie o czasie i przestrzeni w odniesieniu do atomu. Czas i przestrzeń są statystycznymi pojęciami, które stosuje się do zespołu dużej ilości indywidualnych elementów. Byłyby one natomiast bezsensownymi pojęciami podczas pierwszego rozpadu pierwotnego atomu" s.

W rozwiązaniu Lemaître'a niemożliwa jest bliższa charakterystyka fizykalna stanu maksymalnej prostoty ${ }^{6}$. Pierwszym zdarzeniem, jakie może opisać fizyka są procesy rozpadowe w pierwotnym atomie. Dopiero po ich wystąpieniu możliwe jest stosowanie kategorii przestrzeni i czasu.

Sam Lemaître dostrzegał trudności swojego rozwiązania i poważnie liczył się z możliwością, iż z rozwojem przyrodoznawstwa wypracowana zostanie dokładniejsza charakterystyka stanu absolutnej prostoty. To, iż teoria pierwotnego atomu była przedmiotem wielu analiz krytycznych ${ }^{7}$, w jakich wykazywano jej fizykalne trudności, nie prowadzi bynajmniej do falsyfikacji koncepcji aczasowego wszechświata, ponieważ koncepcja ta jest niezależna od krytykowanych założeń teorii Lemaître'a.

3. Wydaje się, że bardziej uzasadnioną byłaby koncepcja aczasowego wszechświata oparta na nowszych analizach zjawiska kolapsu grawitacyjnego czy procesów zachodzących w materii w stanie nadgęstym. Jeśli słuszna jest dopuszczana przez J. B. Zeldowicza i I. D. Nowikowa ${ }^{8}$ możliwość, iż do supergęstych stanów materii nie daje się odnosić wielu pojęć stosowanych w aktualnej fizyce, a wśród nich pojęcia czasoprzestrzeni, wtedy w supergęstym stanie wszechświata niemożliwym byłoby rozróżnienie między wcześniejszym a późniejszym procesem, gdyż same terminy „przed”, „po”, „,wcześniej” i „później” byłyby w takich warunkach bezsensowne semantycznie, ponieważ w rzeczywistości nie istniałyby żadne procesy, jakie dałoby się charakteryzować przy pomocy tych terminów.

5 The Cosmological Constant, w: Einstein, Philosopher Scientist (ed. P. A. Schilpp), New York 1951, 453.

6 Por. The Primaeval Atom Hypothesis and the Problem of the Cluster of Galaxies, w: La Structure et l'Évolution de l'Univers, Bruxelles 1958, 6: „In absolute simplicity no physical question can be raised." Por. też The Beginning of the World from the Point of View of Quantum Theory, „Nature”, 127 (1931) 706.

7 Zob. np. J. Merleau - Ponty, Cosmologie du XXe siècle, Paris 1965, 363-370; A. Dauvillier, Les hypotheses cosmogoniques, Paris 1963, 93; E. Schatzmann, L'origine et évolution des mondes, Paris 1957, 302; F. Cernuschi, S. Codina, A Modification to Lemaitre Cosmogonical Hypothesis, „Revista Matemática y Fisica Teorica”, A 16 (1966) 137.

Rielatiwistskaja astrofizika, Moskwa 1967, 550. 
Analogiczna sytuacja występuje w ujęciu E. R. Harrisona, według którego Einsteinowskie zasady grawitacji można odnosić jedynie do materii o gęstości poniżej $10^{95} \mathrm{~g} . \mathrm{cm}^{-3}$. Materia o wyższej gęstości kieruje się już prawami kosmologii kwantowej, w jakiej najprawdopodobniej nie będzie wprowadzane pojęcie czasu ani przestrzeni ${ }^{9}$.

Podobne rozwiązania przyjmują również G. E. Chew ${ }^{10}$, I. S. Aleksiejew ${ }^{11}$, T. Tati ${ }^{12}$ czy E. J. Zimmerman ${ }^{13}$, twierdząc, iż pojęcie czasu i przestrzeni można bez ograniczeń odnosić tylko do obiektów makrokosmicznych. Absolutnie niedopuszczalne jest jednak odnoszenie tych pojęć do ekstremalnych dziedzin badań, gdzie rola ich mogłaby się okazać podobna do roli eteru $w$ fizyce przełomu XIX/XX wieku ${ }^{14}$. Jeśli przyjmie się rozwijane przez wymienionych autorów hipotezy o nieciągłości przestrzeni i czasu oraz uzna, iż istnieje dolna granica przestrzenno-czasowa $\left(l_{0}, \tau_{0}\right)$, w konsekwencji przyznać trzeba, że rozwijający się zgod̉nie z twierdzeniem Hawkinga-Penrose'a od stanu osobliwego wszechświat przechodził w przeszłości przez stadium aczasowe.

4. Do wniosku o lokalnym tylko charakterze procesów czasowych doszedł w inny sposób jeszcze w latach pięćdziesiątych $R$. Schlegel ${ }^{15}$. Próbując tłumaczyć paradoksalny wówczas fakt, iż czas ewolucji bliskich obiektów kosmicznych wydawał się być dłuższy od czasu ekspansji wszechświata, Schlegel dopuszczał możliwość, iż pojęcie czasu daje się sensownie odnosić tylko do lokalnych układów, zaś bezsensowną jest jego aplikacja do wszechświata jako całości. Ujęcie to wykazuje zbieżność z poglądami L. Boltzmanna, który w początkach naszego stulecia twierdził, iż jeśli rozpatruje się cały wszechświat, bezsensowne jest orzekanie o kierunku upływu czasu, podobnie jak bezsensowne byłyby próby określania kierunków „góra” — „dół” w skali kosmologicznej ${ }^{16}$.

W inny sposób próbuje się uzasadniać wniosek o aczasowym charakterze wszechświata jako całości w koncepcji oscylującego kosmosu. Według opinii M. Čapka ${ }^{17}$ czy J. Merleau-Ponty ${ }^{18}$ model wszechświata

\footnotetext{
9 Zob. Quantum Cosmology, ,Nature”, 215 (1967) 151; Paradox of Classical Particles in Cosmology, ,Ap. J.", 72 (1967) 802.

10 The Dubious Role of the Space Time Continuum in Microscopic Physics, „Science Progress”, 51 (1963) 529.

${ }^{11} \mathrm{~K}$ woprosu o prawomiernosti primienienija ponjatij prostranstwa $i$ wriemieni $w$ fizikie mikromira, w: Prostranstwo $i$ wriemja $w$ sowriemiennoj fizikie, Kijew 1968, 259; Prostranstwo i kwantowaja miechanika, w: Fiłosofskije woprosy kwantowoj fiziki, Moskwa 1970, 230.

1. Concepts of Space - Time in Physical Theories, ,Supplement of the Progress of Theoretical Physics" $(1964,29) 1$.

${ }_{13}$ The Macroscopic Nature of Space - Time, „Amer. J. Phys.”, 30 (1962, 2) 97.

14 Por. Chew art. cyt.

15 The Age of the Universe, „Brit. J. Phil. Sc.”, 5 (1954) 226.

${ }_{16}$ Vorlesungen über die Gastheorie, t. 2, Leipzig 1910, 257.

17 Philosophical Impact of Contemporary Physics, Toronto 1961, 344.

18 Dz. cyt., 335.
} 
oscylującego implikuje tezę o aczasowości, gdyż w modelu tym o każdym zdarzeniu można byłoby powiedzieć zarówno, że wystąpiło przed chwilą $t_{0}$, jak i po tej chwili oraz niemożliwe byłoby rozróżnienie dwóch korelatywnych stanów kolejnych faz rozwojowych wszechświata.

Status przedstawionych rozwiązań fizykalnych dotyczących aczasowego charakteru pewnych procesów kosmicznych jest zróżnicowany. W niektórych przypadkach rozwiązania te są wysoce spekulatywne i nie znajdują zwolenników wśród współczesnych kosmologów. Tak jest np. z rozwiązaniem A. Eddingtona, który wysuwał przypuszczenia, iż w przeszłości we wszechświecie, w jakim nie występowały żadne zmiany nie tylko nie dało się określić kierunku upływu czasu, ale nawet niemożliwe było odróżnienie bytu od niebytu ${ }^{19}$. Podobnie za dowolne i nieuzasadnione uznać można sugestie Čapka i Merleau-Ponty'ego. W kosmologii relatywistycznej bynajmniej nie musi się przyjmować ścisłej identyczności korelatywnych stanów oscylującego wszechświata. Identyczność taką przyjmowano w kosmologii stoików, według których w powtarzających się rytmicznie cyklach występowały te same zdarzenia i osoby ${ }^{20}$. $\mathrm{Na}$ rzecz podobnych spekulatywno-estetycznych ujęć nie można jednak wskazać żadnych racji, można natomiast wysuwać teoretyczne kontrargumenty. Zauważyć trzeba także, iż model wszechświata oscylującego nie musi bynajmniej implikować modelu czasu-okręgu. Dla niektórych koncepcji rozwijającego się cyklicznie kosmosu bardziej właściwym byłby model czasu-spirali lub czasu-rozety.

Całkowicie różny jest status hipotez, jakie wysunęli Zeldowicz, Chew czy I. G. Naan ${ }^{21}$. Hipotezy te konsystentne są z ogólnymi założeniami, jakie zamiast tradycyjnej zasady kosmologicznej przyjął A. L. Zelmanow ${ }^{22}$. W ujęciu radzieckiego kosmologa we wszechświecie ma realizować się cała różnorodność warunków i zjawisk dopuszczanych przez teorie fizykalne. Wzajemne występowanie efektów kwantowych i relatywistycznych prowadzi do procesów, w których tylko w niewielkim stopniu spełniane są prawa ziemskiej fizyki. Efekty takie występować mogą w odległych rejonach wszechświata, poza wszechświatem Friedmana.

Podobne poglądy podziela także K. P. Stanjukowicz, pisząc, iż w innych rejonach wszechświata mogą występować inne prawa przyrody,

19 Czy wszechświat się rozszerza, tłum. A. Wundheiler, Warszawa 1936, 79 n.

20 Zob. H. Diels, W. Kranz, Fragmente der Vorsokratiker, Berlin 19516, 58 B 34.

21 Fundamientalnyje problemy sowriemiennoj astronomii, w: Dialektika $i$ sowriemiennoje jestiestwoznanije, Moskwa 1970, 228.

$22 K$ postanowkie kosmotogiczieskoj problemy. Dopotnienije, w: Trudy II sjezda Wsiesojuznogo astronomo-gieodieziczieskogo obszcziestwa, MIoskwa 1960; Mietagałaktika $i$ wsielennaja, w: Nauka i cziełowiecziestwo, Moskwa 1962. 
źródła energii, prędkość światła czy rozmiary cząstek ${ }^{23}$. Kosmologiczną kor sekwencją takiego starowiska jest przeprowadzone przez Zelmarowa rozróżnienie między całym wszechświatem, wszechświatem w całości a wszechświatem jako całością. Pierwsze z tych pojęć oznacza wszystkie części niezależnie od całości, drugie całość niezależną od części, trzecie całość w stosunku do części składowych. W wyniku tych dystynkcji wszechświatowi jako całości nie można przypisywać pewnych cech charakterystycznych, jakie przypisuje się określonym układom materii, gdyż może okazać się, że posiadają one jedynie lokalny charakter.

\section{III}

Przeprowadzone analizy prowadzą do następujących wniosków ważnych dla filozofii przyrody:

1. Obok klasycznych ujęć filozoficznych, w których orzekało się o powstaniu wszechświata w c z a sie (koncepcja Newtonowska) lub z c z as e m (Augustyn, relacyjne teorie czasu), możliwe są rozwiązania, w których istniałby poczatek czasu we wszechświecie. W wariantach takich mógłby istnieć początek czasu, lecz nie implikowałoby to wcale absolutnego początku trwania wszechświata.

2. Zmiany wymagałyby przyjmowane przez diamatyków określenia materii jako istniejącej w czasie i przestrzeni. Musiałoby ulec reinterpretacji twierdzenie Lenina, iż „poruszająca się materia nie może poruszać się inaczej, jak tylko w przestrzeni i czasie" ${ }^{24}$. Modyfikacji wymagałaby także teza o wieczności materii, gdyż wieczność tę tradycyjnie zwykło się pojmować jako brak początku czasowego.

3. Tezy o wieczności wszechświata lub istnieniu jego początku czasowego można przyjąć jako aksjomat albo postulat, niemożliwe jest jednak ich udowodnienie fizykalne lub filozoficzne. Ponieważ analizy filozoficzne tego zagadnienia dotyczą tego samego czasu, jaki w aspekcie empiriometrycznym ujmuje przyrodnik, rozwiązaniạ czysto filozoficzne pozbawione podtekstu fizykalnego wydają się być w tej dziedzinie niemożliwością. Stąd też przy próbach konstrukcji odnośnych argumentów filozof musi uwzględniać fakt, że dopuszczalna w perspektywach nauk szczegółowych bezsensowność empiryczna i semantyczna pytania o czas istnienia wszechświata może pozbawić wartości jego argumenty, które choć sformułowane są $\mathrm{w}$ innych perspektywach pojęciowych, to jednak odnoszą się do tego samego przedmiotu materialnego, o jakim traktuje fizyka i kosmologia. W konsekwencji, w filozoficznych analizach dotyczących

23 Problemy teorii grawitacji i elemientarnych czastic, Moskwa 1966, 272.

24 Matierializm i empiriokriticizm. Połnoje sobranije soczinienij, t. 18, 181. 
problemu kreacji wszechświata wydaje się być wątpliwym rozwiązanie, w którym zagadnienie to sprowadza się do pytania o początek trwania c zas owe go kosmosu. Skutkiem tego celowym byłoby uzależnienie podobnych analiz nie od czasowości wszechświata, lecz od innego jege aspektu, np. przygodności.

4. Jeśli wszechświat w przeszłości znajdował się w stadium aczasowym, bezsensownym semantycznie okazuje się pytanie o jego absolutny początek czasowy. Dlatego też bliższych analiz wymaga zagadnienie, czy możliwy jest przekład semantyczny tego pytania, by po wprowadzeniu niepustych (= nie dotyczących czasu) predykatów treść jego została niezmieniona, zaś samo pytanie nie miało pseudoproblemowego charakteru ${ }^{25}$.

25 Próby translacji semantycznej klasycznego pytania o początek czasowy wszechświata przedstawione zostały w pracach: K. Kłósak, Problem sensouności pytania o początek czasowy wszechświata, „Anal. Crac.”, 5-6 (1973-74)291--297; J. Życiński, Zagadnienie filozoficznych implikacji fizykalnych ujęć stanu szczególnego modeli kosmologicznych, Praca doktorska, Kraków 1976, 102-105.

THE PROBLEM OF ATEMPORAL CHARACTER OF THE UNIVERSE ACCORDING TO NEW COSMOLOGICAL THEORIES

\section{S U M M A R Y}

The article presents general characteristic of cosmological theories concerning a possibility of the existence of atemporal phase in cosmic evolution. These hypotheses were presented among others by G. Lemaitre, Ya. Zeldovich, I. D. Novikov, K. Čapek and J. Merleau-Ponty. Hypotheses about atemporal universe have important philosophical consequences showing possibility of the existence of processes where many terms generally used cannot be extrapolated. Besides traditional philosophical theories about beginning of the Universe with time or in time may be developed new theories about beginning of time in the Universe. Presented hypotheses show also a necessity of a modification of the traditional matter definition (as existing in time and space) and necessity of a reinterpretation of the classical question about temporal beginning of the Universe. 